Send your letters to the editor, British

Dental Journal, 64 Wimpole Street, London

W1G8YS E-mail bdj@bda.org

Priority will be given to letters less than 500

words long. Authors must sign the letter,

which may be edited for reasons of space.

\section{Smoking clinics}

Sir, we read with interest the fact that the Eastman Dental Hospital now runs support to stop smoking clinics for patients. However, we must disagree with the fact that they are the first dental initiative of this kind in England. Three of the staff at our dental surgery completed the advisor training in January 2006 and have been offering appointments to patients since then.

The practice runs regular oral health clinics and is very involved in the promotion of oral health locally. The 'support to stop' service has proven to be popular with patients who would rather come to the dental surgery than go to the doctor's.

We wish the Eastman luck with their initiative and hope that they have the success that we have had.

\section{J. Harrington \\ L. Redwood \\ Paulton}

doi: 10.1038/sj.bdj.2007.34

\section{Ask your PCT}

Sir, I would like to congratulate Aubrey Sheiham on his little gem of a paper (BDJ 2006; 201: 625-626). In this paper Professor Sheiham points out that preschool children with severe untreated dental caries suffer from pain and sepsis and fail to thrive.

However - and this was new to me - after comprehensive dental treatment these children gained weight and improved their quality of life. Professor Sheiham concludes that dental treatment for these children has real benefits and that obviously prevention of dental caries would be better.

The recent Water Act 2003 opens up real possibilities of progress with water fluoridation; the Act requires Water Companies to fluoridate when, following public consultation, they are asked to do so by a Strategic Health Authority.

We would see real benefits for preschool children three years from the start of new fluoridation schemes. ${ }^{1}$

Local sections of the BDA should ask their PCTs:

- what is the level of untreated dental decay in their 5-year-old children

- how is the PCT's oral health plan addressing the issue

- has the PCT considered the possibility of water fluoridation?

\section{Lennon}

\section{Sheffield}

1. Booth J M, Mitropoulos CM, Worthington HV.A comparison between the dental health of 3-year-old children living in fluoridated Huddersfield and nonfluoridated Dewsbury in 1989. Comm Dent Health 1992; 9: 151-157.

doi: 10.1038/sj.bdj.2007.35

\section{Two across and one down}

Sir, while travelling on the train recently, two young women came and sat opposite me. Their conversation fell to dental matters. One, it seemed, had a problem which visits to three dentists had failed to resolve; indeed, the problem had only become worse. Could her friend recommend to her a competent dentist? 'Oh, extorted her friend, 'Don't talk to me about dentists! I think they're all incompetent, but just in different ways!' Deciding discretion was the better part of valour, I buried myself deeper in my crossword.

\section{Evans}

Dundee

doi: 10.1038/sj.bdj.2007.36

\section{Fit to sweep roads}

Sir, I read with great interest your article in the $B D J(2006 ; 201: 485)$, as I am an HIV positive dental surgeon. I ceased NHS dentistry in summer 2005 as I wished to move abroad.

I was diagnosed HIV positive in February 2006 when I applied for a mortgage on a new property. I was unable to move abroad and at the same time could not return to my former career. I did ask my occupational medicine consultant if I would be able to treat HIV positive patients at my local dental hospital. He wrote to the Expert Advisory Group on AIDS. They replied stating that a HIV positive dentist could treat a HIV positive patient under certain circumstances, viz:

- the HIV positive patients give informed consent to being treated by a HIV

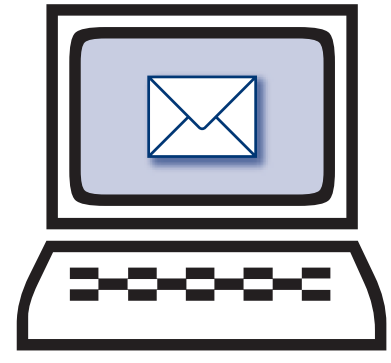

positive dentist

- procedures are restricted

- the dentist remains under regular Occupational Medicine supervision

- the dentist meets all other GDC criteria regarding fitness to practise

- the dentist seeks advice from the GDC first.

One further point of note: my OM consultant suggested I apply to the NHSSS for Early Retirement Benefits because of my medical condition. The NHSSS initially agreed to pay me Ill Health Retirement Benefit as I was unable to practise clinical dentistry. When the Pensions Department of the DPB realised I had already left the NHS, they said I had to reapply for Preserved Pension Benefits. This time my application was refused because, in their opinion, I was fit enough to do any job (they even suggested I become a road sweeper) and to reapply when I reached 65 , or sooner if I died! Name and address supplied doi: 10.1038/sj.bdj.2007.37

\section{The caring face}

Sir, the recent opinion piece and editorial (BDJ 2006; 201: 485, 497-499), which highlight the problems faced by dentists who are diagnosed as HIV positive, are brought into sharp focus by the experience related, so painfully, by the author of This was something that happened to someone else (BDJ 2006; 201: 697-698).

Sadly, the author is not alone. The BDA Benevolent Fund is aware of other GDPs in a similar situation who are facing significant financial difficulties. Banned from practising their profession in their thirties or forties, with borrowings against a future income that no longer exists, they find that obtaining a post outside dentistry has been impossible on the grounds that they are 'overqualified'. To compound their problems, as selfemployed workers, they are not eligible for the range of state support available to employees. Without the financial assistance of the Benevolent Fund, which is of necessity barely enough to meet their basic needs, their situation would be dire.

The look-back exercise is, as mentioned 
by your author, an additional problem for the practitioner. In one case the exercise gave the practitioner's home address in the local paper, leading to such pressure on him that he had to move away. Clinical depression, almost inevitably, followed. There is also the problem of conflicting advice. One of our beneficiaries was advised by his doctor that there was no need for him to stop working, so he carried on for several weeks after his diagnosis.

I am disappointed to read that your author felt that he did not find the help from his fellow professionals that he might have expected, but would like to reassure your readers that the Benevolent Fund, as the caring face of the profession and the dental trade, is always there, in the strictest confidence, to help any of our colleagues in their time of need.

Air Vice-Marshal Ian McIntyre

Chairman of the Board of Trustees, BDA Benevolent Fund doi: 10.1038/sj.bdj.2007.38

\section{A grave injustice}

Sir, I was very moved on reading the harrowing account of the treatment meted out to a colleague diagnosed with HIV (BDJ 2006; 201: 485). I find the lack of compassion for a colleague who has fallen foul of a life-risk shared with the rest of humanity to be quite sickening, and find it difficult to imagine the grief and emotional trauma this man must have suffered as a result of the ostracism, injustice, disgraceful insensitivity and abandonment that he encountered at the hands of those in so-called 'caring professions', in addition to the devastation attributable to the diagnosis itself.

Sufficiently strong adjectives are difficult to find.

HIV is an increasing global problem, and potentially affects every man, woman and child on the planet. No one can afford to ignore it. The number of diagnoses in the UK continues to increase, and with that increase comes an increase in risk to all of us, as dentists in our professional lives, and as ordinary people in our private lives.

As dentists we have to deal with blood and body fluids on a daily basis, and as we are told it is unethical to refuse to treat a patient on the basis of their being HIV positive, we are obliged to take the risks that go with that. As there are many times more HIV positive patients than HIV positive dentists, it must be obvious who is statistically more at risk from whom, in the event of a mishap during treatment. This occupational risk must be fully recognised and acknowledged, and it would be totally unethical, in my opinion, to deny a colleague anything less than the fullest possible support in the event of a positive diagnosis. Once diagnosed, a dentist becomes a patient: a patient who is just as entitled to dignified and sympathetic support from the healthcare system as any other taxpayer.

The author's courage is to be admired in referring to the mode of infection, in this case, as a 'personal misdemeanour'.

Certainly, HIV can be acquired through ignorance, carelessness, recklessness, folly, and poor judgement, of which we can all be guilty at times, but it can also be acquired through sheer bad luck. In any of these circumstances, a death sentence, however much postponed, is a very heavy price to pay.

As fallible, feeling human beings, dentists are as susceptible as anyone else to the traumas and misfortunes of life and the personal vulnerabilities that can result from them. They cannot make their lives risk-free any more than the rest of humanity and have as much right as anyone else to a private life and all that means. Even people in apparently stable, monogamous relationships can be at risk. Existing sexual partners can cheat, and new ones may not fully disclose a previous sexual history. This prospect was brought starkly home to me several years ago when my own marriage of 25 years failed, and I suddenly realised how the process of finding another relationship would take me into new 'risk territory'. How many of us are prepared to avoid such risk altogether and become celibate hermits? Or are dentists expected to give up a normal personal life in order to safeguard their livelihood, or to supposedly protect patients whom evidence shows are not at risk and who, collectively, pose many more times the risk to us than we do to them? The idea is absurd.

This case brings into stark reality how little recognition, understanding or concern is given by the Establishment to the welfare of those in the caring professions, in the same way that combatant troops wounded or otherwise traumatised in battle are regarded simply as 'cannon-fodder' and abandoned by the MOD.

We have come to expect shabby treatment from the Establishment, but to realise that we now have elements of an inhuman, prejudiced, discriminatory, hypocritical, abusive, ruthless, narrowminded, dog-eat-dog culture, devoid of empathy and compassion, pervading our own and other healthcare professions frankly disgusts me.

I sincerely hope that the author of this article will at last gain some measure of healing from publishing his story and from 
any supportive correspondence that he richly deserves to receive for exposing this grave injustice for the benefits of us all.

\section{G. Raven}

Birmingham

doi: $10.1038 /$ sj.bdj.2007.40

\section{Exasperated sighs}

Sir, we write with sighs of exasperation in response to two letters published in the journal. B. Qureshi (Incidental findings BDJ 2006; 201: 689) presented the case of a maxillary sinus 'polyp' identified by panoramic radiography, using this as a reminder to readers of the importance of 'thorough radiographic examination'. The maxillary sinus mucous retention cyst (erroneously called 'polyp') is an extremely common incidental finding that rarely, if ever, requires treatment. While we applaud Mr Qureshi for seeing the anomaly on the panoramic radiographs, we are concerned that his letter might be interpreted as a support for routine screening using panoramic radiography. In this particular case, identifying an asymptomatic and trivial condition did not help the patient and may have resulted in an unnecessary hospital referral.

In a letter in the same edition of the journal, K. Gündüz (Supernumerary molars BDJ 2006; 201: 688) describes a case of unerupted, asymptomatic, supernumerary molars on a panoramic radiograph taken as part of 'routine dental treatment'. While colleagues may have uttered 'Ooh! Fancy that!' upon reading this letter and seeing the radiograph, the case once again shows routine panoramic radiography identifying anomalies that do not justify treatment.

Radiography without adequate clinical indication ('Justification') is illegal under the Ionising Radiation (Medical Exposure) Regulations 2000. It is not only, however, an issue of radiation protection. What is often forgotten is that someone is paying for the unnecessary radiographs. These costs may increase if the consequence is an unnecessary hospital referral. There are ample scientific publications illustrating that routine panoramic radiography is not justifiable. The two cases described here may have the insidious effect of reinforcing erroneous beliefs about the value of radiographic screening. We refer readers to readily available and evidencebased guidance ${ }^{1,2}$ on this subject. A basic guideline is, however, that radiographs should be prescribed for patients individually on the basis of clinical signs and symptoms. In both the cases described above, had this approach been followed, no panoramic radiographs would have been taken and neither patient would have suffered as a consequence.

\section{K. Horner}

\section{E. Rushton}

Manchester

1. Selection criteria for dental radiography. $2^{\text {nd }}$ edn. London: Faculty of General Dental Practitioners (UK), 2004

2. Radiation Protection 136. European Guidelines on Radiation Protection in Dental Radiology. Luxembourg: Office for Official Publications of the European Communities, 2004. (available as a free PDF download at http://ec.europa.eu/energy/nuclear/ radioprotection/publication/136_en.htm.)

doi: 10.1038/sj.bdj.2007.39

\section{The threat of hostility}

Sir, I have received and been witness to a barrage of profanities in my dental practice, and also been threatened with physical violence. When faced with an unruly patient looking for the opportunity to vent their anger, we are often put in an awkward position.

The NHS directive guidelines strictly condemn the verbal and physical abuse of their staff. Perpetrators can expect to face prosecution if they deviate from what is considered to be 'civilised behaviour'.

This unfortunately gives little comfort to dental teams facing the threat of hostility from patients and the bureaucracy of our legal system.

An incident took place in our practice where the dentist was subjected to vulgar language and aggressive behaviour. Due to the racial nature of the attack, the police gave the case top priority, and the offender will soon appear in court.

Is this strike one for the 'good guys'? Hardly. Discrimination and abuse come in many forms and a racist comment should not be the primary factor for an investigation to be undertaken.

Of course living in a society where political correctness distorts the ideals of free speech and 'democracy', it is not surprising that troublemakers' racist remarks receive the greatest response.

A little conflict from patients may be expected every once in a while, but it is a travesty that the Department of Health and the PCT do not play a prominent role in the protection of NHS staff throughout the dental and medical profession. After all it is our taxes that help fund them.

Contrary to what some may assume, we are not gluttons for punishment, and we do not go to work to be abused by disgruntled members of the public who have issues that need to be addressed before they come for their treatment.

Subsequently there are some who, justifiably, feel that their time and energy is being squandered, due to a lack of comprehension on the part of a government network whose agenda contradicts the principles set out to supposedly 'safeguard' all personnel, regardless of colour or ethnicity.

S. Abassalty

Practice Manager

Addlestone

doi: 10.1038/sj.bdj.2007.41

\section{Erroneous assumption}

Sir, I read the article by Tickle et al. (BDJ 2006; 201: 769-773) on dental screening in schools with great interest. It was particularly noteworthy that the concept of negative consent was acceptable to all groups interviewed, but not to the Department of Health. The Department's decision was based on the entirely erroneous assumption that physical contact between the screening dentist inevitably takes place during screening. In my lengthy career I estimate that I have screened over 50,000 children but have made contact with less than $0.1 \%$ of these. I suspect that others have achieved less contact. The Department's decision is based on ignorance of what can be done and indeed what is usually done.

The lack of health benefit from screening found by the same authors in a previous article supports the belief of many dentists who undertake screening - that it is an ineffective use of resources. For screening to be stopped if it is ineffective seems to be a sensible evidence-based decision. For it to be stopped or rendered even more inefficient due to an uninformed assumption is nonsensical. The authors give evidence that dental health can reasonably be considered to ultimately be a parental responsibility. It is time to investigate the use of measures that can help those parents who find it difficult to meet this responsibility rather than encouraging reliance on an outdated and ineffective public health measure.

\section{Wanless}

Head of Salaried Primary Care Dental Service Central and Eastern Cheshire PCT doi: 10.1038/sj.bdj.2007.42 